\title{
How do online sports gambling disorder patients compare with land-based patients?
}

\author{
ANA ESTÉVEZ ${ }^{1}$, RAQUEL RODRÍGUEZ ${ }^{1}$, NOELIA DÍAZ ${ }^{1}$, ROSER GRANERO ${ }^{2,3}$, GEMMA MESTRE-BACH ${ }^{2,4}$, \\ TREVOR STEWARD ${ }^{2,4}$, FERNANDO FERNÁNDEZ-ARANDA ${ }^{2,4,5}$, NEUS AYMAMI' ${ }^{4}$, MÓNICA GÓMEZ-PEÑA ${ }^{4}$, \\ AMPARO DEL PINO-GUTIÉRREZ ${ }^{6}$, MARTA BAÑO ${ }^{4}$, LAURA MORAGAS ${ }^{4}$, NÚRIA MALLORQUÍ-BAGUÉ ${ }^{2,4}$, \\ HIBAI LÓPEZ-GONZÁLEZ ${ }^{1,7}$, PAULA JAUREGUI ${ }^{1}$, JAIONE ONAINDIA ${ }^{1}$, VIRGINIA MARTÍN-ROMERA ${ }^{8}$, \\ JOSÉ M. MENCHÓN ${ }^{4,5,9}$ and SUSANA JIMÉNEZ-MURCIA ${ }^{2,4,5 *}$ \\ ${ }^{1}$ Department of Personality, Psychological Assessment and Treatment of the University of Deusto, Bilbao, Spain \\ ${ }^{2}$ Ciber Fisiopatología Obesidad y Nutrición (CIBERObn), Instituto de Salud Carlos III, Madrid, Spain \\ ${ }^{3}$ Departament de Psicobiologia i Metodologia de les Ciències de la Salut, Universitat Autònoma de Barcelona, Barcelona, Spain \\ ${ }^{4}$ Pathological Gambling Unit, Department of Psychiatry, Bellvitge University Hospital - IDIBELL, Barcelona, Spain \\ ${ }^{5}$ Department of Clinical Sciences, Faculty of Medicine, University of Barcelona, Barcelona, Spain \\ ${ }^{6}$ Nursing Department of Mental Health, Public Health, Maternal and Child Health, Nursing School, University of \\ Barcelona, Barcelona, Spain \\ ${ }^{7}$ International Gaming Research Unit, Nottingham Trent University, Nottingham, UK \\ ${ }^{8}$ Departament de Psicologia Clínica, Universitat Autònoma de Barcelona, Barcelona, Spain \\ ${ }^{9}$ Ciber de Salud Mental (CIBERSAM), Instituto de Salud Carlos III, Madrid, Spain
}

(Received: March 3, 2017; revised manuscript received: September 1, 2017; accepted: October 1, 2017)

\begin{abstract}
Background and aims: Recent technological developments have brought about notable changes in the way people gamble. The widespread use of mobile Internet devices and gambling websites has led to a significant leap in the number of people who recreationally gamble. However, for some, gambling can turn into a psychiatric disorder resembling substance addiction. At present, there is a shortage of studies examining differences between adults with gambling disorder (GD) who exclusively make sports bets online, GD patients that are non-sports Internet gamblers, and offline gamblers. Therefore, this study was undertaken to determine the differences between these three groups, considering sociodemographic, personality, and clinical characteristics. Methods: The sample consisted of 2,743 treatment-seeking male patients from the Pathological Gambling Unit at a university hospital. All patients met DSM-5 criteria for GD. Results: We found that gamblers who exclusively engaged in non-sports Internet gambling activities were younger than offline gamblers and online sports gamblers. Non-sports Internet gamblers were also more likely to have greater levels of debt compared with offline gamblers. In terms of personality characteristics, our sample displayed low levels of self-directedness and cooperativeness and high levels of novelty seeking. In addition, online sports gamblers obtained higher scores in persistence than non-sports Internet gamblers and offline gamblers. Discussion and conclusion: Although differences if terms of gambling severity were not identified between groups, GD patients who exclusively bet online appear to possess distinct personality characteristics and higher debt levels compared with offline gamblers.
\end{abstract}

Keywords: gambling disorder, Internet, online gambling, personality, betting

\section{INTRODUCTION}

Increased Internet availability has brought about rapid advances to our day-to-day lives and with them, changes in the way people gamble. For most, gambling serves as little more than a form of entertainment; for other individuals however, the wide range of betting and gaming activities offered through Internet-enabled devices can transform into a disorder with serious social and psychological consequences (Deans, Thomas, Daube, \& Derevensky, 2016). As opposed to land-based (i.e., offline) gambling, Internet gambling allows for betting to be conducted without social interaction and provides continuous, instant feedback (Bonnaire, 2012;
Gainsbury, 2015). These factors raise concerns that Internet gambling could contribute to the development of gambling disorder (GD) or lead individuals who would otherwise not regularly gamble, to develop a pathological use of Internet gambling platforms (Gainsbury \& Wood, 2011; Griffiths, 2006). In Spain, e.g., most gambling activity remains landbased, though online gambling grew from representing just

* Corresponding author: Susana Jiménez-Murcia; Head of Pathological Gambling Unit, Department of Psychiatry, Bellvitge University Hospital, c/Feixa Llarga, s/n, 08907 L'Hospitalet de Llobregat, Barcelona, Spain; Phone: +34 9326079 88; Fax: +34 9326076 58; E-mail: sjimenez@bellvitgehospital.cat 
$20.15 \%$ of gambling revenues in 2013 to $26.48 \%$ in 2015 (Dirección General de Ordenación del Juego, 2015).

Different risk factors for developing problem gambling have been identified, with personality dimensions, such as impulsivity, being strongly associated with GD. Associations between gambling behavior and impulsivity, however, may be shaped by a variety of factors, including socioeconomic status, reward and punishment sensitivity, and gender and age of gambling onset (Echeburúa, González-Ortega, de Corral, \& Polo-López, 2011; Hing, Russell, Vitartas, \& Lamont, 2015; Jiménez-Murcia et al., 2010, 2016). These findings have led to the development of highly influential subtyping models that incorporate developmental, cognitive, and personality factors in categorizing various etiological pathways to GD subtypes (Blaszczynski \& Nower, 2002). These subtypes are characterized by behaviorally conditioned gambling behavior, emotionally vulnerable gambling behavior, and antisocial impulsive gambling behavior. Other research using the five-factor model of personality has identified the overall personality profile of GD patients as being one that combines high impulsivity with emotional vulnerability (Bagby et al., 2007). Little is known, however, on the personality traits of GD patients who exclusively gamble online and whether the aforementioned subtyping models can be applied to these patients (Hing, Russell, Gainsbury, \& Blaszczynski, 2015).

Research thus far has identified a disproportionate number of men, young people, and students among online gamblers (Kairouz, Paradis, \& Nadeau, 2012; Wood \& Williams, 2009). Shared symptomatology has also been reported when comparing online with offline gambling (Odlaug, Marsh, Kim, \& Grant, 2011). For example, Del Pino-Gutiérrez et al. (2016) found that alcohol abuse is common in both profiles, although some studies suggest that online gamblers consume more alcohol and illicit drugs compared with offline gamblers (Blaszczynski, Russell, Gainsbury, \& Hing, 2016). Similarly, research has proposed that online gamblers are more at risk of developing gambling-related problems and engaging co-occurring risky behaviors (Kairouz et al., 2012; Wood \& Williams, 2007). One particularly troubling aspect of online gambling is that Internet gamblers are less likely to recognize their gambling problems than offline gamblers (Petry, 2006). Given that Internet gambling typically occurs in private, Internet gamblers run the increased risk of continuing their worsening problematic behavior until a crisis point is reached (Gainsbury, Russell, Hing, Wood, \& Blaszczynski, 2013).

Recently developed Internet-delivered approaches have shown promise as a viable treatment option for problem gamblers who are reluctant to seek face-to-face treatment (Canale et al., 2016; Myrseth, Brunborg, Eidem, \& Pallesen, 2013). A recent pilot randomized controlled trial in Sweden tested the feasibility of an Internet-based treatment for problem gamblers and concerned significant others, and found that this novel intervention successfully lowered the symptoms of problem gambling and measures of depression and anxiety for gamblers (Nilsson, Magnusson, Carlbring, Andersson, \& Gumpert, 2017). Lowering barriers to treatment via Internet-delivered approaches is especially relevant in Sweden since more than half $(55 \%)$ of the gamblers in this country report playing online (Swedish Gambling
Authority, 2015). Still, a recent meta-analysis found that face-to-face treatments were more effective than self-guided treatments in reducing problematic gambling behavior, suggesting that the intensity of treatment moderates the impact of therapy (Goslar, Leibetseder, Muench, Hofmann, \& Laireiter, 2017). Being that uptake of both face-to-face and online treatment is significantly lower among problem Internet gamblers compared with problem land-based gamblers (Hing, Russell, Gainsbury, et al., 2015), more information is needed in what ways these groups differ.

The burgeoning area of Internet gambling has also given gamblers access to a greater variety of games than what is normally available in offline (land-based) venues and research suggests that online gamblers' playing patterns differ significantly in many aspects from offline gamblers (Elton-Marshall, Leatherdale, \& Turner, 2016). One study, using an online survey to assess the behavior of 6,682 Australian gamblers, found that online gamblers were more likely to bet on sports and engage in a greater number of gambling activities than offline gamblers (Gainsbury et al., 2013). On the other hand, offline gamblers were more likely to use electronic gaming machines (EGM) and to attribute EGM gambling as being the predominant cause of gambling problems. Such broader patterns of gambling behavior in online gamblers are concerning given that recent research has identified that breadth involvement in gambling activity, particularly the number of types of games played over a defined period, contributes more to problem gambling than playing specific games (e.g., lottery, casino, and Internet gambling) (Hing, Russell, Vitartas, et al., 2015; LaPlante, Nelson, \& Gray, 2014). Regularly engaging in live action sports betting, in particular, has been identified as a risk factor for problem gambling, and identifying the characteristics that distinguish online sports gamblers from online gamblers who engage in other activities (e.g. poker, online bingo, etc.) is an area that warrants further attention (Hing, Russell, Vitartas, et al., 2015). It is also possible that online sports gamblers constitute a unique phenotype in that they are characterized by being mostly young, male, single, educated, and employed full time or as a full-time student (Hing, Russell, Vitartas, et al., 2015).

To the best of our knowledge, a limited number of studies have identified the sociodemographic and personality characteristics associated with online sports betting and non-sports Internet gambling in a large, treatmentseeking population. To date, most studies have used general population samples (Moreau, Chabrol, \& Chauchard, 2016). It is also worth noting that research examining online gamblers has largely not distinguished between those who exclusively gamble online and those who use both land-based and Internet modalities. Gaining a deeper understanding of the differences between these groups in a clinical sample could be useful with regard to developing GD treatment strategies for this population.

Thus, the objective of this study was to assess the clinical, sociodemographic, and personality profiles of treatment-seeking GD patients who exclusively bet on sports online, non-sports Internet gamblers, and land-based gamblers. We hypothesized that both Internet gambling groups (sports and non-sports) would be younger and 
present higher gambling severity levels compared with landbased gamblers. We chose not to develop specific hypotheses regarding differences in personality traits between the studied groups given that no studies to date have examined these characteristics when taking sport and non-sports Internet gambling into account.

\section{METHODS}

\section{Participants}

A sample of 2,743 male GD patients who sought treatment at the Gambling Disorder Unit at a university hospital between 2005 and 2015 was considered. All participants were diagnosed according to DSM-IV-TR criteria (First, Gibbon, Spitzer, \& Williams, 1996). These patients were recodified post hoc using DSM-5 criteria and no participants were excluded because all of them continued to meet diagnostic criteria. They were classified into three groups according to the gambling modality they reported in the face-to-face interview: offline gambling $(n=2,558)$, online sports betting $(n=64)$, and non-sports Internet gambling $(n=121)$. Data from patients who exclusively played land-based games were placed in the offline group, whereas patients engaging exclusively in online/mobile sports betting were placed in the online sports betting group. Data from GD patients who reported exclusively gambling online on non-sports-related activities (e.g., poker, casino games, etc.) were placed in the nonsports Internet gambling group. This classification has been made since differences between the three gambling modalities have been observed at the clinical level (Blaszczynski et al., 2016).

Exclusion criteria for the study were the presence of an intellectual disability or an active psychotic disorder. Moreover, female patients were excluded from the study sample to their disproportionately low prevalence in comparison with male GD patients. Finally, mutual exclusivity criterion was required to include the patients in these three groups, i.e., the gambling modalities considered in this study did not occur simultaneously. Therefore, patients who participated in a combination of land-based and Internet gambling activity $(n=41,1.47 \%)$ were excluded from this analysis to allow for the estimation and comparison of the phenotype profile and specific clinical state of each group.

\section{Measures}

South Oaks Gambling Screen (SOGS; Lesieur \& Blume, 1987). This self-report questionnaire consists of 20 items to identify problematic and non-problematic gambling. The total score can range from 0 to 20 , but scores over 4 are considered indicative of GD. The Spanish validation of this questionnaire (Echeburúa, Báez, Fernández, \& Páez, 1994) showed good psychometric properties (Cronbach's $\alpha=.97$, test-retest reliability 0.98 , internal consistency 0.94 , and convergent validity 0.92 ).

DSM-5 criteria (American Psychiatric Association $[A P A], 2013)$. Patients were diagnosed with pathological gambling if they met DSM-IV-TR criteria (APA, 2000). It should be noted that with the release of the DSM-5, the term pathological gambling was replaced with GD (APA, 2013). All patient diagnoses were reassessed and recodified post hoc and only patients who met DSM-5 criteria for GD were included in our analysis.

Temperament and Character Inventory - Revised (TCI-R; Cloninger, 1999). The TCI-R is a reliable and valid 240-item questionnaire, which measures seven personality dimensions: four temperaments (novelty seeking, harm avoidance, reward dependence, and persistence) and three character dimensions (self-directedness, cooperativeness, and self-transcendence). All items are measured on a 5-point Likert scale. The scales in the Spanish revised version showed adequate internal consistency (Cronbach's $\alpha-$ a mean value of .87; Gutiérrez-Zotes et al., 2004).

Additional data. Demographic, clinical, and social/ family variables related to gambling were measured using a semi-structured, face-to-face clinical interview described elsewhere (Jiménez-Murcia, Aymamí-Sanromà, GómezPeña, Álvarez-Moya, \& Vallejo, 2006). Some of the gambling behavior variables covered in this interview included the age of gambling onset, the mean and maximum monetary spending in a single gambling episode, financial debts, gambling activity preferences, and the total amount of accumulated debts.

Cronbach's $\alpha$ of internal consistency values for the psychometrical scales in the sample of the study are included in Table 2.

\section{Procedure}

Patients were assessed by trained and licensed psychologists and psychiatrists with more than 15 years of experience treating GD patients. Questionnaires were completed (requiring approximately $2 \mathrm{hr}$ ) before initiating outpatient treatment.

Following the completion of the assessment material, all patients meeting criteria for GD were offered the option of attending weekly outpatient cognitive behavioral therapy sessions for 16 weeks. This treatment program has already been described elsewhere (Jiménez-Murcia et al., 2006) and its short- and medium-term effectiveness has been reported (Jiménez-Murcia et al., 2007, 2012).

\section{Statistical analysis}

Statistical analyses were carried out with SPSS20 for Windows. Chi-square tests $\left(\chi^{2}\right)$ compared categorical variables between groups and analysis of variance (ANOVA) compared quantitative variables. The comparisons for clinical profile were adjusted for the patients' age. Effect size for the comparison between groups was estimated through Cohen's- $d$ coefficient, considering $|d|>0.50$ to be moderate effect size and $|d|>0.80$ to be good effect size. Increases in Type-I error due to multiple comparisons were controlled with the Bonferroni-Finner correction, a method included in the family-wise error rate stepwise procedures, which offers more statistical power than the classical Bonferroni correction (Finner, 1993). 


\section{Ethics}

The study procedures were carried out in accordance with the Declaration of Helsinki. The Institutional Review Board of the Bellvitge University Hospital approved the study. All subjects were informed about the study and all provided informed consent.

\section{RESULTS}

\section{Characteristics of the sample}

Patients were classified into three groups according to their gambling preferences: offline gambling (2,588 patients, $94.3 \%$ ), online sports gamblers (64 patients, 2.3\%), and online gamblers (any type of online game involving betting money - e.g., poker, blackjack, etc.) (121 patients, 4.4\%). Table 1 contains a comparison of the sociodemographic variables between the study groups. No statistical differences were found between groups with regard to origin (non-immigrant vs. immigrant), employment status, or monthly income. The offline gambling group presented the lowest of education levels $(61.6 \%$ of the sample only completed primary school studies), whereas the non-sports Internet gambling group had the highest proportion of patients with a university level of education (21.5\%). Compared with both offline gambling and online sports betting groups, the non-sports Internet gambling group included a higher proportion of single patients $(51.2 \%$ vs. $33.1 \%$ and $34.4 \%$, respectively). No statistical differences emerged between offline gamblers and online sports gamblers in terms of age, age of gambling onset, gambling duration, and income levels. However, the non-sports Internet gambling group reported lower ages, lower age of gambling onset, and a shorter duration of the gambling problem. The non-sports Internet gambling group also had significantly higher monthly incomes compared with the offline and online sports gambling groups.

\section{Comparison between groups in gambling and personality characteristics}

Table 2 contains an ANOVA comparing the clinical profiles of the gambling subtypes, adjusted for patients' age. Considering gambling spending activity, patients in the online sports gambling group made higher maximum bets compared with their offline counterparts. Similarly, the offline gambling group had lower cumulate debts compared with the online groups. With respect to personality traits, patients in the online sports gambling group obtained lower scores in persistence compared with the other two groups.

The final three rows of Table 2 contain information on the prevalence of substance addictions (tobacco use, alcohol abuse, and other drug abuse) for each gambling type, and a comparison between groups. No statistical differences were found in the prevalence of drug abuse, but the proportion of use/abuse of tobacco and alcohol was higher for the offline gambling group compared with the online gambling subtypes.

\section{DISCUSSION}

The aim of this study was to compare the sociodemographic and clinical characteristics of treatment-seeking GD patients who exclusively made sports bets online with non-sports Internet GD patients and GD patients who did not gamble online (i.e., offline gamblers). We also compared the personality traits of the three different groups in this study sample to identify personality profiles based on gambling activity preferences.

As hypothesized and in line with studies examining risk factors for the development of problem online gambling, the GD patients in the non-sports Internet gambling group were significantly younger than offline gamblers (Gainsbury, 2015; Kairouz et al., 2012). Interestingly, and contrary to our hypothesis, only non-sports Internet gamblers were found to be younger than offline gamblers. This could be indicative of younger players being especially drawn to the variety of gambling activities available on Internet gambling platforms (Petry, 2006). Indeed, researchers have identified a positive association between younger age and diverse engagement in gambling activities (Gainsbury, Russell, Blaszczynski, \& Hing, 2015). Subsequently, other studies have found involvement in a greater number activities to be linked to higher rates of gambling problems (Gainsbury et al., 2015; LaPlante et al., 2014), although this study did not specifically examine the number of different activities participants in each group were involved in.

We also found that online sports gamblers were more likely to make larger maximum bets than offline gamblers, and that both online gambling groups had greater cumulate debts than GD patients in the offline group. The greater financial impact of online gambling could be influenced by the fact that the virtual nature of gambling online environments creates the perception that gamblers are not playing with real money and can therefore take greater risks (Deans et al., 2016). The widespread availability of Internet gambling and the instant feedback that it provides are thought to be particularly appealing to younger gamblers, who use online platforms with greater ease than older gamblers (Moreau et al., 2016). Advertising for online sports gambling also uses persuasive techniques, such as high-volume exposure, attractiveness, pervasiveness, and repetitiveness, to establish bonds with popular sport culture (McMullan \& Miller, 2008). These strategies may influence product consumption and lead to the normalization of damaging gambling patterns (Lindsay et al., 2013). However, contrary to our hypothesis, no differences were found in DSM-5 and SOGS severity levels between offline gamblers and the sports and non-sports Internet gambling groups.

Regarding personality traits, the online sport betting group endorsed higher persistence scores than the other study groups. Given that this group also presented riskier betting behavior and higher gambling-related debts in comparison with the offline group, this finding coincides with studies reporting that high levels of persistence scores may be indicative of greater gambling problems (Moragas et al., 2015). In these lines, high levels of persistence have been associated with compulsivity and this trait is seen as being characteristics across psychiatric disorders 
Online sports betting and gambling disorder

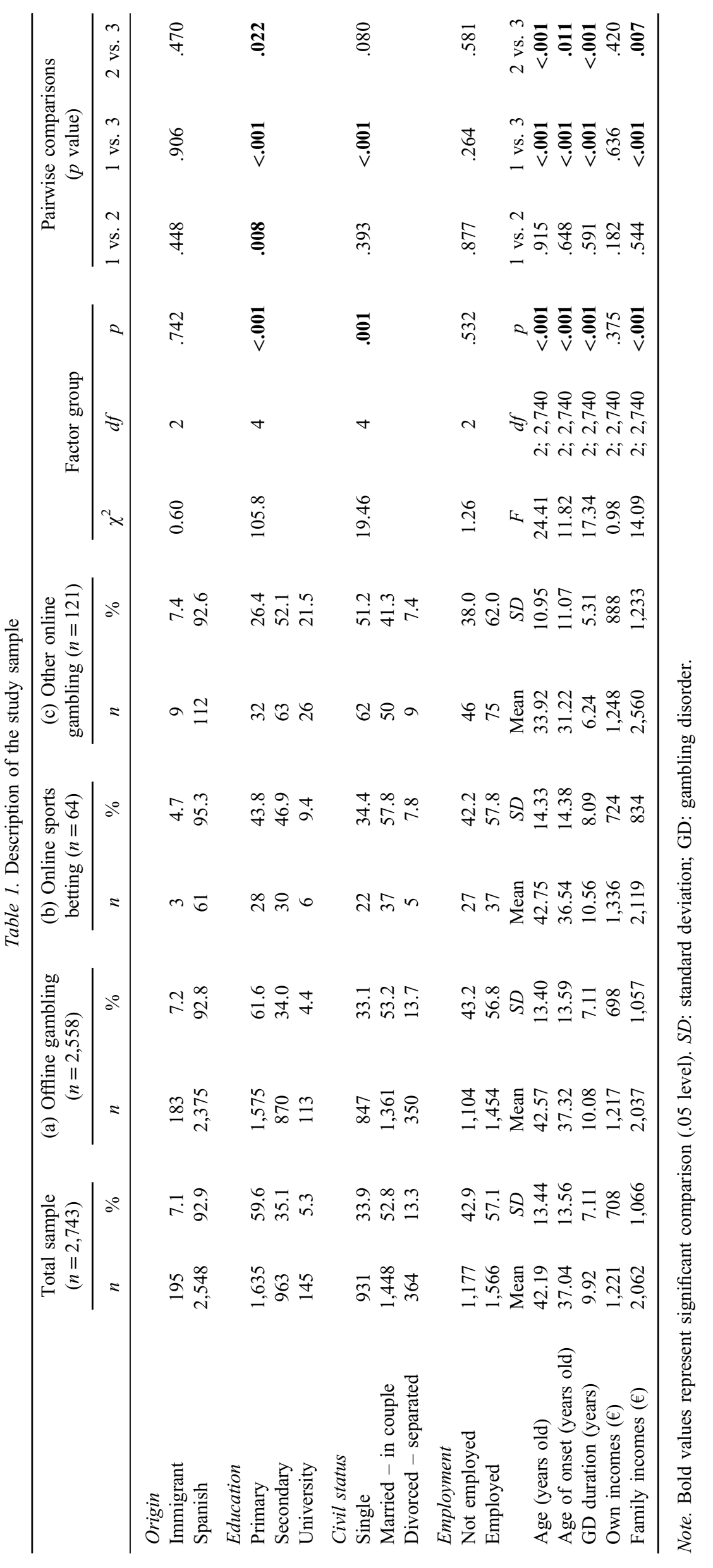


Estévez et al.

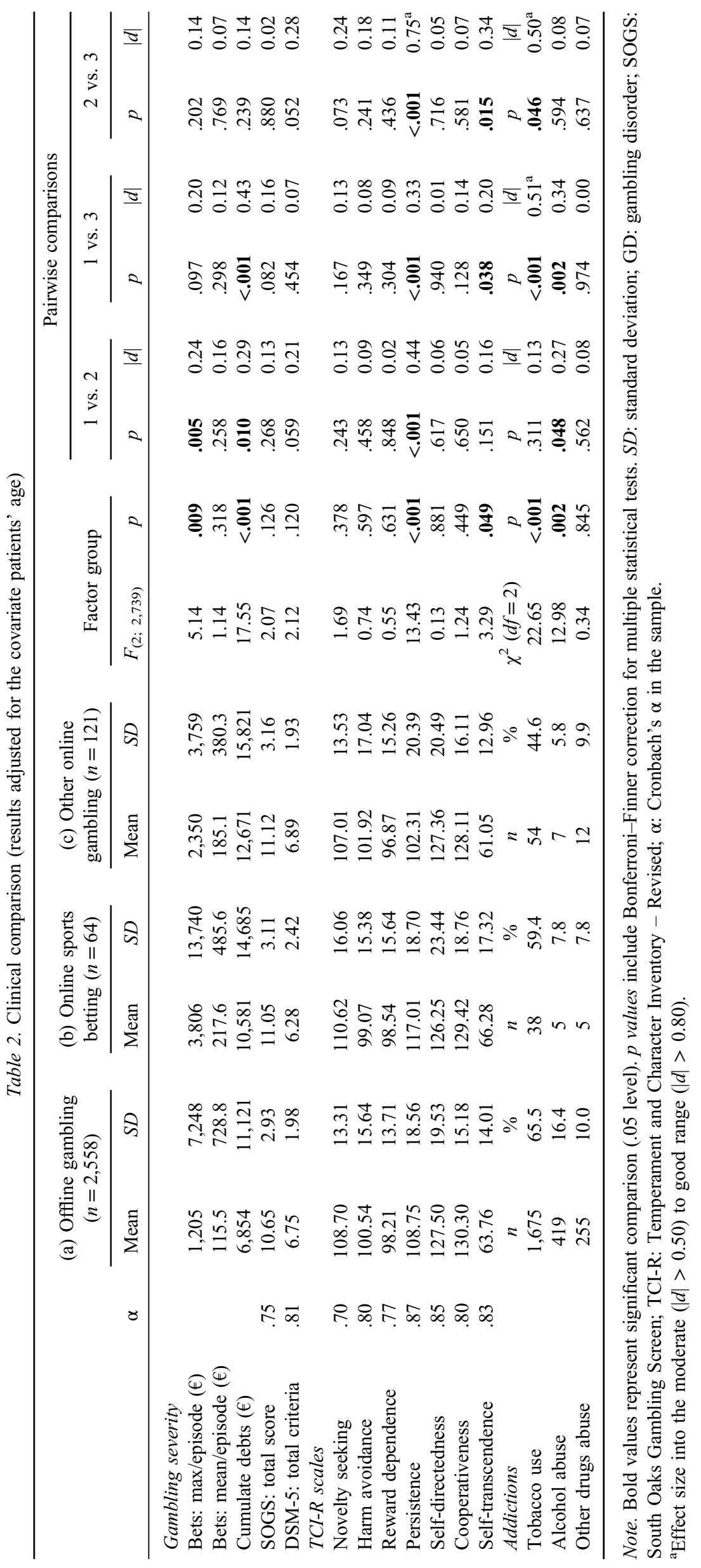


(Atiye, Miettunen, \& Raevuori-Helkamaa, 2015; Belloch, Roncero, \& Perpiñá, 2016; Lavender et al., 2017).

In reference to the other personality dimensions explored in this study, no significant differences were observed between the three study groups. On one hand, our findings uphold, in accordance with Black et al. (2015), that both online and offline GD patients present high scores in novelty seeking compared with population norms. In this vein, other studies have identified that elevated scores in this dimension can be linked to overall gambling severity (Aymamí et al., 2015; Black et al., 2015). On the other hand, literature about personality traits and GD suggests that low levels of selfdirectedness and cooperativeness are typical features of this disorder (Forbush et al., 2008), mainly characterized by immature and dishonest behavior (Nordin \& Nylander, 2007). Relatedly, the GD patients in this study also obtained low scores in both dimensions when compared with population norms.

Therefore, the absence of relevant differences between the three study groups in reference to the other personality traits suggests that the phenotypic personality pattern presented among GD patients is similar, even if the gambling modality differs (online vs. offline). Considering that all the study samples met the same diagnostic criteria and therefore showed the same GD symptomatology, it is not entirely surprising that the personality profiles did not differ greatly between groups.

\section{Limitations}

There are several limitations to this study. First, all data were collected from men who sought treatment. Future studies should aim to include and compare female participants. Moreover, the lack of a control group does not allow for the exploration of variability between clinical groups, especially in terms of personality traits. In addition, possibly due to higher awareness of this condition within land-based settings, the number of offline gambling patients in our sample was vastly higher than the number of sports and non-sports Internet GD patients. It should also be noted that all the patients who made up our sample were voluntarily seeking treatment and therefore are not be representative of all gamblers; literature suggests that younger gamblers might be less likely to seek treatment and this could explain some of the age differences observed in our sample (Petry, 2006). Future research should include larger, more balanced samples so as to overcome this limitation. In this same vein, the patients who participated in a combination of land-based and Internet gambling activities were excluded. In addition, the patients included in our sample were recruited during an extended time span and the accessibility and pervasiveness of online gambling has increased since recruitment began. As such, it is possible that the profiles of online gamblers have changed during this period. Finally, the total number of gambling activities for each patient was not evaluated in this study, although different studies suggest that Internet gamblers appear to participate in a greater variety of gambling activities than land-based gamblers (Gainsbury et al., 2015).

\section{CONCLUSIONS}

Problematic online gambling is a growing social issue in developed countries. There is ongoing debate as to how best classify GD patients considering that it is a heterogeneous disorder. This study provides greater understanding of GD patient profiles according to gambling activity preferences. Online sports gamblers, in particular, appear to represent an especially vulnerable group, as they displayed riskier gambling behaviors than the other studied groups. Additional empirical evidence is needed to broaden our understanding of online GD phenotypes and to develop innovative treatment options for these patients. Recent studies have evidenced that web-based treatments may be an effective method of decreasing gambling-related distress and promoting help-seeking in otherwise hard-to-reach online gamblers.

Funding sources: This manuscript and research were supported by grants from Instituto de Salud Carlos III (PI14/00290, CIBERObn, CIBERsam, and Fondos FEDER) and Ministerio de Economía y Competitividad (PSI2015-68701-R). Both CIBERObn and CIBERSAM are an initiative of ISCIII. GM-B is supported by a predoctoral grant of AGAUR (2016FI_B 00568). HL-G is funded by a postdoctoral fellowship from the Basque government (POS_2015_1_0062).

Authors' contribution: AE, JMM, SJ-M, and FF-A contributed to the development of the study conceptualization and design. RG and VM-R performed the formal statistical analysis. NA, MG-P, AP-G, MB, LM, and NM-B conducted the research and investigation processes of this study, especially data collection. TS, GM-B, RG, FF-A, and SJ-M aided with our interpretation of data. SJ-M, FF-A, and JMM obtained funding. SJ-M, RG, AE, FF-A, and JMM supervised the study. AE, RR, ND, HL-G, PJ, JO, TS, and GM-B were involved in the creation and writing of the initial draft. TS, SJ-M, RG, and GM-B were involved in editing and preparing the final draft of the manuscript, including pre- and post-publication stages. The authors RR and ND contributed equally to this work.

Conflict of interest: The authors declare no conflict of interest.

\section{REFERENCES}

American Psychiatric Association [APA]. (2000). Diagnostic and statistical manual of mental disorders (4th ed., text rev.). Washington, DC: American Psychiatric Association.

American Psychiatric Association [APA]. (2013). Diagnostic and statistical manual of mental disorders (5th ed.). Washington, DC: American Psychiatric Association.

Atiye, M., Miettunen, J., \& Raevuori-Helkamaa, A. (2015). A meta-analysis of temperament in eating disorders. European Eating Disorders Review, 23(2), 89-99. doi:10.1002/erv.2342 
Aymamí, N., Jiménez-Murcia, S., Granero, R., Ramos-Quiroga, J. A., Fernández-Aranda, F., Claes, L., Sauvaget, A., GrallBronnec, M., Gómez-Peña, M., Savvidou, L. G., Fagundo, A. B., del Pino-Gutierrez, A., Moragas, L., Casas, M., Penelo, E., \& Menchón, J. M. (2015). Clinical, psychopathological, and personality characteristics associated with ADHD among individuals seeking treatment for gambling disorder. BioMed Research International, 2015, 1-11. doi:10.1155/2015/965303

Bagby, R. M., Vachon, D. D., Bulmash, E. L., Toneatto, T., Quilty, L. C., \& Costa, P. T. (2007). Pathological gambling and the five-factor model of personality. Personality and Individual Differences, 43(4), 873-880. doi:10.1016/j.paid.2007.02.011

Belloch, A., Roncero, M., \& Perpiñá, C. (2016). Obsessional and eating disorder-related intrusive thoughts: Differences and similarities within and between individuals vulnerable to OCD or to EDs. European Eating Disorders Review, 24(6), 446454. doi:10.1002/erv. 2458

Black, D. W., Coryell, W. H., Crowe, R. R., Shaw, M., McCormick, B., \& Allen, J. (2015). Personality disorders, impulsiveness, and novelty seeking in persons with DSM-IV pathological gambling and their first-degree relatives. Journal of Gambling Studies, 31(4), 1201-1214. doi:10.1007/s10899014-9505-y

Blaszczynski, A., \& Nower, L. (2002). A pathways model of problem and pathological gambling. Addiction, 97(5), 487499. doi:10.1046/j.1360-0443.2002.00015.x

Blaszczynski, A., Russell, A., Gainsbury, S., \& Hing, N. (2016). Mental health and online, land-based and mixed gamblers. Journal of Gambling Studies, 32(1), 261-275. doi:10.1007/ s10899-015-9528-z

Bonnaire, C. (2012). Internet gambling: What are the risks? L'Encéphale, 38(1), 42-49. doi:10.1016/j.encep.2011.01.014

Canale, N., Vieno, A., Griffiths, M. D., Marino, C., Chieco, F., Disperati, F., Andrioloa, S., \& Santinello, M. (2016). The efficacy of a web-based gambling intervention program for high school students: A preliminary randomized study. Computers in Human Behavior, 55, 946-954. doi:10.1016/j. chb.2015.10.012

Cloninger, C. R. (1999). The temperament and character inventoryRevised. St. Louis, MO: Center for Psychobiology of Personality.

Deans, E. G., Thomas, S. L., Daube, M., \& Derevensky, J. (2016). I can sit on the beach and punt through my mobile phone?: The influence of physical and online environments on the gambling risk behaviours of young men. Social Science \& Medicine, 166, 110-119. doi:10.1016/j.socscimed.2016.08.017

Del Pino-Gutiérrez, A., Fernández-Aranda, F., Granero, R., Tárrega, S., Valdepérez, A., Agüera, Z., Håkansson, A., Sauvaget, A., Aymamí, N., Gómez-Peña, M., Moragas, L., Baño, M., Honrubia, M., Menchón, J. M., \& Jiménez-Murcia, S. (2016). Impact of alcohol consumption on clinical aspects of gambling disorder. International Journal of Mental Health Nursing, 26(2), 121-128. doi:10.1111/inm.12221

Dirección General de Ordenación del Juego. (2015). Memoria anual 2015. Madrid, Spain: Ministerio de Hacienda y Administraciones Públicas.

Echeburúa, E., Báez, C., Fernández, J., \& Páez, D. (1994). Cuestionario de juego patológico de South Oaks (SOGS): Validación española. [South Oaks Gambling Screen (SOGS): Spanish validation]. Anális Modific Cond, 20, 769-791.

Echeburúa, E., González-Ortega, I., de Corral, P., \& PoloLópez, R. (2011). Clinical gender differences among adult pathological gamblers seeking treatment. Journal of Gambling Studies, 27(2), 215-227. doi:10.1007/s10899-010-9205-1

Elton-Marshall, T., Leatherdale, S. T., \& Turner, N. E. (2016). An examination of Internet and land-based gambling among adolescents in three Canadian provinces: Results from the youth gambling survey (YGS). BMC Public Health, 20, 769-791. doi:10.1186/s12889-016-2933-0

Finner, H. (1993). On a monotonicity problem in step-down multiple test procedures. Journal of the American Statistical Association, 88(423), 920-923. doi:10.1080/01621459.1993. 10476358

First, M., Gibbon, M., Spitzer, R., \& Williams, J. (1996). Users guide for the structured clinical interview for DSM IV Axis I disorders - Research version (SCID-I, version 2.0). New York, NY: New York State Psychiatric Institute.

Forbush, K. T., Shaw, M., Graeber, M. A., Hovick, L., Meyer, V. J., Moser, D. J., Bayless, J., Watson, D., \& Black, D. W. (2008). Neuropsychological characteristics and personality traits in pathological gambling. CNS Spectrums, 13(4), 306315. doi:10.1017/S1092852900016424

Gainsbury, S. M. (2015). Online gambling addiction : The relationship between Internet gambling and disordered gambling. Current Addiction Reports, 2(2), 185-193. doi:10.1007/ s40429-015-0057-8

Gainsbury, S. M., Russell, A., Blaszczynski, A., \& Hing, N. (2015). Greater involvement and diversity of Internet gambling as a risk factor for problem gambling. European Journal of Public Health, 25(4), 723-728. doi:10.1093/eurpub/ckv006

Gainsbury, S. M., Russell, A., Hing, N., Wood, R., \& Blaszczynski, A. (2013). The impact of Internet gambling on gambling problems: A comparison of moderate-risk and problem Internet and non-Internet gamblers. Psychology of Addictive Behaviors, 27(4), 1092-1101. doi:10.1037/a0031475

Gainsbury, S. M., \& Wood, R. (2011). Internet gambling policy in critical comparative perspective : The effectiveness of existing regulatory frameworks. International Gambling Studies, 11(3), 309-323. doi:10.1080/14459795.2011.619553

Goslar, M., Leibetseder, M., Muench, H. M., Hofmann, S. G., \& Laireiter, A.-R. (2017). Efficacy of face-to-face versus selfguided treatments for disordered gambling: A meta-analysis. Journal of Behavioral Addictions, 6(2), 142-162. doi:10.1556/ 2006.6.2017.034

Griffiths, M. (2006). Addiction trends: Internet v casino gambling. Casino and Gaming International, 2, 85-91.

Gutiérrez-Zotes, J., Bayón, C., Montserrat, C., Valero, J., Labad, A., Cloninger, C., \& Fernández-Aranda, F. (2004). Temperament and character inventory revised (TCI-R). Standardization and normative data in a general population sample. Actas Españolas de Psiquiatria, 32, 8-15.

Hing, N., Russell, A. M. T., Gainsbury, S. M., \& Blaszczynski, A. (2015). Characteristics and help-seeking behaviors of Internet gamblers based on most problematic mode of gambling. Journal of Medical Internet Research, 17(1), e13. doi:10. 2196/jmir.3781

Hing, N., Russell, A. M. T., Vitartas, P., \& Lamont, M. (2015). Demographic, behavioural and normative risk factors for gambling problems amongst sports bettors. Journal of Gambling Studies, 32(2), 625-641. doi:10.1007/s10899-0159571-9

Jiménez-Murcia, S., Álvarez-Moya, E. M., Granero, R., Aymamí, M. N., Gómez-Peña, M., \& Jaurrieta, N. (2007). 
Cognitive-behavioral group treatment for pathological gambling: Analysis of effectiveness and predictors of therapy outcome. Psychotherapy Research, 17(5), 544-552. doi:10. 1080/10503300601158822

Jiménez-Murcia, S., Alvarez-Moya, E. M., Stinchfield, R., Fernández-Aranda, F., Granero, R., Aymamí, N., Gómez-Peña, M., Jaurrieta, N., Bove, F., \& Menchón, J. M. (2010). Age of onset in pathological gambling: Clinical, therapeutic and personality correlates. Journal of Gambling Studies, 26(2), 235-248. doi:10.1007/s10899-009-9175-3

Jiménez-Murcia, S., Aymamí, N., Gómez-Peña, M., Santamaría, J. J., Alvarez-Moya, E., Fernández-Aranda, F., Granero, R., Penelo, E., Bueno, B., Moragas, L., Gunnard, K., \& Menchón, J. M. (2012). Does exposure and response prevention improve the results of group cognitive-behavioural therapy for male slot machine pathological gamblers?. The British Journal of Clinical Psychology, 51(1), 54-71. doi:10.1111/j.2044-8260.2011.02012.x

Jiménez-Murcia, S., Aymamí-Sanromà, M., Gómez-Peña, M., Álvarez-Moya, E., \& Vallejo, J. (2006). Protocols de tractament cognitivoconductual pel joc patològic $i$ d'altres addiccions no tòxiques [Cognitive-behavioral treatment protocols for pathological gambling and other non-substance addictions]. Barcelona, Spain: Hospital Universitari de Bellvitge, Departament de Salut, Generalitat de Catalunya.

Jiménez-Murcia, S., Fernández-Aranda, F., Mestre-Bach, G., Granero, R., Tárrega, S., Torrubia, R., Aymamí, N., GómezPeña, M., Soriano-Mas, C., Steward, T., Moragas, L., Baño, M., Del Pino-Gutiérrez, A., \& Menchón, J. M. (2016). Exploring the relationship between reward and punishment sensitivity and gambling disorder in a clinical sample: A path modeling analysis. Journal of Gambling Studies, 33(2), 579-597. doi:10.1007/ s10899-016-9631-9

Kairouz, S., Paradis, C., \& Nadeau, L. (2012). Are online gamblers more at risk than offline gamblers? Cyberpsychology, Behavior and Social Networking, 15(3), 175-180. doi:10.1089/cyber. 2011.0260

LaPlante, D. A, Nelson, S. E., \& Gray, H. M. (2014). Breadth and depth involvement: Understanding Internet gambling involvement and its relationship to gambling problems. Psychology of Addictive Behaviors, 28(2), 396-403. doi:10.1037/a0033810

Lavender, J. M., Goodman, E. L., Culbert, K. M., Wonderlich, S. A., Crosby, R. D., Engel, S. G., Mitchell, J. E., Le Grange, D., Crow, S. J., \& Peterson, C. B. (2017). Facets of impulsivity and compulsivity in women with anorexia nervosa. European Eating Disorders Review, 25(4), 309-313. doi:10.1002/erv. 2516

Lesieur, H. R., \& Blume, S. B. (1987). The South Oaks Gambling Screen (SOGS): A new instrument for the identification of pathological gamblers. The American Journal of Psychiatry, 144(9), 1184-1188. doi:10.1176/ajp.144.9.1184
Lindsay, S., Thomas, S., Lewis, S., Westberg, K., Moodie, R., \& Jones, S. (2013). Eat, drink and gamble: Marketing messages about "risky" products in an Australian major sporting series. BMC Public Health, 13(1), 719. doi:10.1186/1471-245813-719

McMullan, J. L., \& Miller, D. (2008). All in! The commercial advertising of offshore gambling on television. Journal of Gambling Issues, 22, 230-251. doi:10.4309/jgi.2008.22.6

Moragas, L., Granero, R., Stinchfield, R., Fernández-Aranda, F., Fröberg, F., Aymamí, N., Gómez-Peña, M., Fagundo, A. B, Islam, M. A., del Pino-Gutiérrez, A., Agüera, Z., Savvidou, L. G., Arcelus, J., Witcomb, G. L., Sauchelli, S., Menchón, J. M., \& Jiménez-Murcia, S. (2015). Comparative analysis of distinct phenotypes in gambling disorder based on gambling preferences. BMC Psychiatry, 15(1), 86. doi:10.1186/s12888015-0459-0

Moreau, A., Chabrol, H., \& Chauchard, E. (2016). Psychopathology of online poker players: Review of literature. Journal of Behavioral Addictions, 5(2), 155-168. doi:10.1556/2006.5. 2016.035

Myrseth, H., Brunborg, G. S., Eidem, M., \& Pallesen, S. (2013). Description and pre-post evaluation of a telephone and Internet based treatment programme for pathological gambling in Norway: A pilot study. International Gambling Studies, 13(2), 205-220. doi:10.1080/14459795.2012.759610

Nilsson, A., Magnusson, K., Carlbring, P., Andersson, G., \& Gumpert, C. H. (2017). The development of an Internet-based treatment for problem gamblers and concerned significant others: A pilot randomized controlled trial. Journal of Gambling Studies, Advance online publication. doi:10.1007/ s10899-017-9704-4

Nordin, C., \& Nylander, P.-O. (2007). Temperament and character in pathological gambling. Journal of Gambling Studies, 23(2), 113-120. doi:10.1007/s10899-006-9049-x

Odlaug, B. L., Marsh, P. J., Kim, S. W., \& Grant, J. E. (2011). Strategic vs nonstrategic gambling: Characteristics of pathological gamblers based on gambling preference. Annals of Clinical Psychiatry, 23(2), 105-112.

Petry, N. M. (2006). Internet gambling: An emerging concern in family practice medicine? Family Practice, 23(4), 421-426. doi:10.1093/fampra/cml005

Swedish Gambling Authority. (2015). Allma nheten om spel 2015 [The general public on gambling 2015].

Wood, R. T., \& Williams, R. J. (2007). Problem gambling on the Internet: Implications for Internet gambling policy in North America. New Media \& Society, 9(3), 520-542. doi:10.1177/ 1461444807076987

Wood, R. T., \& Williams, R. J. (2009). Internet gambling: Prevalence, patterns, problems, and policy options: Final report (Vol. 5). Guelph, Canada: Ontario Problem Gambling Research Centre. 